\title{
High rates of gastroesophageal cancers in patients with dyspepsia undergoing upper gastrointestinal endoscopy in Uganda
}

\section{(9) $\circledast \Theta$}

\author{
Authors \\ Ronald Mbiine'1, Cephas Nakanwagi², Olivia Kituuka \\ Institutions \\ 1 Department of Surgery, Makerere University College of \\ Health Sciences, Kampala, Uganda \\ 2 Endoscopy Unit, Mulago National Referral Hospital, \\ Kampala, Uganda
}

submitted 20.1.2021

accepted after revision 12.3 .2021

Bibliography

Endosc Int Open 2021; 09: E997-E1000

DOI 10.1055/a-1480-7231

ISSN 2364-3722

(c) 2021. The Author(s).

This is an open access article published by Thieme under the terms of the Creative Commons Attribution-NonDerivative-NonCommercial License, permitting copying and reproduction so long as the original work is given appropriate credit. Contents may not be used for commercial purposes, or adapted, remixed, transformed or built upon. (https://creativecommons.org/licenses/by-nc-nd/4.0/)

Georg Thieme Verlag KG, Rüdigerstraße 14,

70469 Stuttgart, Germany

Corresponding author

Ronald Mbiine, P.O. Box 7072 Mulago Hill Road, Kampala,

Uganda

mbiineron@gmail.com

\section{ABSTRACT}

Background and study aims Dyspepsia is the most common presenting symptom in the gastrointestinal clinic of
Mulago National Referral hospital. The etiology is essentially not fully described in our patient population. This study was therefore conducted to establish the causes of dyspepsia based on endoscopic diagnosis among patients with dyspepsia seeking care at the National Referral hospital of Uganda.

Patients and methods This retrospective study conducted in the endoscopy unit of Mulago hospital reviewed 356 patient endoscopy reports spanning January 2018 to July 2020 with a focus on those with a referral indication of dyspepsia. Age and sex were the independent variables of interest while the endoscopy findings as reported by the endoscopist were the outcome variable of interest.

Results Of the 356 endoscopy reports reviewed, 159 met the inclusion criterion of dyspepsia as the indication. Participant mean age was 47.7 years ( \pm 16.53 ) with the majority $(25.79 \%)$ in the fifth decade while the male to female ratio was 1. The majority of patients had organic dyspepsia $(90.57 \%)$ while the commonest finding was gastritis 69 (43.4\%). Gastroesophageal cancers represented (18) $11.32 \%$ of all findings. There was a positive association between age $>50$ years with gastroesophageal cancers (7.639) as well as age $<50$ years and functional dyspepsia (2.794); however, all these were not statistically significant $(P=0.006$ and $(P=0.095$, respectively).

Conclusions Organic/structural dyspepsia comprises over $90 \%$ of investigated dyspepsia with $11 \%$ comprising cancer among patients seeking endoscopy at the National Referral Hospital of Uganda.

\section{Introduction}

Dyspepsia, which by definition is the presence of one or more of the symptoms of epigastric pain, bloating, post-prandial fullness, early satiation, and retrosternal pain [1], is estimated to affect up to $50 \%$ of individuals globally [2] with an estimated higher prevalence in low and middle income countries, particularly Africa with the highest prevalence of uninvestigated dyspepsia [3]. In one community study conducted in rural Uganda, more than $50 \%$ of the respondents reported having had symptoms of dyspepsia [4]. The majority of dyspepsia in Africa is un- investigated with patients often treated symptomatically. This creates a challenge as treatable diseases including malignancies are often missed only to present in very advanced stages. The paucity of information on dyspepsia in sub-Saharan Africa (SSA) also affects development of clinical and policy strategies of mitigating causes including cancer of the stomach which is the most prevalent gastrointestinal malignancy in SSA. SSA is projected to have a more than $73 \%$ increase in gastrointestinal cancers by 2030 , way more than the $59 \%$ global estimate [5]. With uninvestigated dyspepsia masking this growing burden, there is a need to fully understand the characteristics of dys- 
peptic symptoms in our population seeking care for dyspepsia. In one study in western Uganda, the majority of dyspeptic patients had gastritis [6] while in a study done in Kenya a significant majority had functional dyspepsia [7], contrasting with a study in Nigeria where only $8 \%$ of the participants had functional dyspepsia [8]. Other studies conducted in Uganda are representative of specific regions [9] and therefore non-generalizable. This variability in findings, therefore, warrants a characterization of dyspepsia in Uganda at a national referral center that receives a more diverse patient population from all regions in Uganda. This research, therefore, characterizes the etiology of dyspepsia as seen on upper gastrointestinal endoscopy of patients seeking care at the National Referral Hospital of Uganda.

\section{Patients and methods}

This was a retrospective study conducted in the Endoscopy Unit of Mulago National Referral Hospital of Uganda. This hospital has a bed capacity 1500 at any given time and has $100 \%$ occupancy consisting of primarily referrals from other hospitals around the country. The gastrointestinal outpatient clinics comprise one medical and one surgical outpatient unit, which are attended by patients referred from other hospitals with an average attendance of 2500 to 3000 patients per year. It is from this population that patients referred for upper gastrointestinal endoscopy are sent to the endoscopy unit. The endoscopy unit also directly receives referrals from other hospitals in the region.

Despite receiving patients from all over the country, the majority of patients seeking care at the endoscopy unit are from the surrounding central region of Uganda. Endoscopy services are provided by experienced physicians and surgeons in the unit and the diagnoses made are based on their observation of the clinical characteristics of the disease entity. Where necessary, biopsies are performed on suspicious tissues for further evaluation. For gastritis, "endoscopic gastritis," which refers to the diagnosis of gastritis based on observations seen on endoscopy, was the primary method of diagnosis and in severe forms, biopsy with histological diagnosis of gastritis would be performed. Diagnosis of gastritis is occasionally further classified into superficial, hemorrhagic, erosive, atrophic, and metaplastic.

Endoscopy reports of all patients that underwent an upper gastrointestinal endoscopy procedure between January 2019 and January 2020 were reviewed. The referring doctor's diagnosis or reason for recommending an endoscopy as written on the referral note was reviewed for inclusion in the study.

\section{Inclusion criteria}

Referral reports with the diagnosis or reason for referral registered as either dyspepsia or uninvestigated dyspepsia by the referring doctor were included in the study. For referral notes that had a different diagnosis besides dyspepsia, the diagnosis or reason for referral was compared to the definition of dyspepsia based on the ROME IV criteria [10] of having any of the following: epigastric pain, epigastric fullness, early satiety, or burning epigastric pain. When the referral reason or diagnosis met the
- Table 1 Participant demographic characteristics.

\begin{tabular}{|l|l|l|}
\hline Parameter & Frequency & Percentage or \pm SD \\
\hline Age & & \\
\hline$<30$ & 29 & 18.24 \\
\hline $31-40$ & 27 & 16.98 \\
\hline $41-50$ & 28 & 17.61 \\
\hline $51-60$ & 41 & 25.79 \\
\hline $60-70$ & 17 & 10.69 \\
\hline$>70$ & 17 & 10.69 \\
\hline Mean age & 47.698 & \pm 16.53 \\
\hline Sex & & \\
\hline Male & 79 & 59.69 \\
\hline Female & 80 & 50.31 \\
\hline
\end{tabular}

ROME IV criteria, the patient was included in the study. Reports whose reason for referral was reported that did not meet the inclusion criteria, including some listed as dysphagia, odynophagia, gastrointestinal bleeding, or screening endoscopy, all were excluded from the study. For referral notes in which more than one reason was included, such as dysphagia with dyspepsia, these were also included as long as the indication of dyspepsia was included in the referral note/endoscopy request. The endoscopies were performed by qualified endoscopists in the unit.

The primary outcome variable of interest was the endoscopic diagnosis as reported on the endoscopy report by the endoscopist. The findings were classified as organic/structural if a physical lesion was observed on endoscopy while the presence of normal findings was classified as functional dyspepsia. Other variables included the participant demographics including the age, sex, tribe, and region.

Variables were captured in an Epi-data database and later exported to Stata 16 software for analysis. Statistical analysis took on a descriptive approach. All variables were categorical and therefore described using proportions along with their percentages.

\section{Results}

In total, 356 patient endoscopy reports were evaluated and of these, 159 met the inclusion criteria.

The male to female ratio of the study population was one while the mean age was 47.70 years $( \pm 16.53)$ with the majority (25.79\%) in the fifth decade of life ( $\triangleright$ Table 1$)$. On the primary outcome variables of the endoscopic diagnosis, $90.57 \%$ of patients had organic dyspepsia, meaning that there was a diagnosis of a structural disease while $9.43 \%$ of the participants had normal findings despite the dyspeptic symptoms ( $\triangleright$ Table 2 ), a condition referred to as functional dyspepsia.

The most common findings on endoscopy were gastritis followed by gastroesophageal reflux disease. Gastroesophageal 
- Table 2 Endoscopic findings.

\begin{tabular}{|l|c|c|}
\hline Diagnosis & Frequency & Percentage \\
\hline Normal findings & 15 & 9.43 \\
\hline Gastritis & 69 & 43.4 \\
\hline Gastric ulcers & 3 & 1.89 \\
\hline Duodenal ulcers & 5 & 3.14 \\
\hline Hiatal hernia & 4 & 2.52 \\
\hline GERD & 31 & 19.5 \\
\hline Gastric cancer & 11 & 6.92 \\
\hline Esophageal cancer & 7 & 4.40 \\
\hline Esophagitis & 2 & 1.26 \\
\hline Others & 12 & 7.55 \\
\hline GERD, gastroesophageal reflux disease. & \\
\hline
\end{tabular}

- Table 3 Dyspepsia classification.

\begin{tabular}{|l|c|c|}
\hline Dyspepsia classification & Frequency & Percentage \\
\hline Functional dyspepsia & 15 & 9.43 \\
\hline Organic dyspepsia & 144 & 90.57 \\
\hline
\end{tabular}

cancers (gastric and esophageal cancer) comprised $11.32 \%$ of all diagnoses ( $\triangleright$ Table 3 ). Of the 18 patients who had a diagnosis of gastrointestinal cancer, $61 \%$ had gastric cancer while the rest had esophageal cancer ( $\triangleright$ Table 4$)$.

On evaluation for the association between the two independent variables of age and sex with the primary outcome variable, age was stratified into two categories: $<50$ years and $>50$ years. We found no association between age and gastritis with a chi square coefficient of 0.612 while the presence of gastroesophageal cancers was strongly associated with age $>50$ years with a positive coefficient of $7.639(P=0.006)$ while that of functional dyspepsia was $2.794(P=0.095)$. However, these variables were not statistically significant in our study population. In regard to the location of the cancer, there was no association with age or sex. Similarly, there was no association between sex and the overall endoscopy diagnosis.

\section{Discussion}

We conducted this study with the intention of describing endoscopy findings among patients who underwent upper gastrointestinal endoscopy for dyspepsia as it is the most common presenting symptom and indication for upper gastrointestinal endoscopy at the Gastrointestinal Surgery Clinic in Mulago National Referral hospital in Uganda.

We found that the majority of patients who presented for upper gastrointestinal endoscopy were aged 51 to 60 years. In Uganda, it is recommended but not mandatory that the presence of dyspeptic symptoms should be investigated with
- Table4 Location of gastroesophageal malignancies.

\begin{tabular}{|l|l|l|}
\hline Tumor type and location & Frequency (N) & Percentage (\%) \\
\hline Esophagus (7) & 1 & 5.56 \\
\hline Proximal third & 5 & 27.78 \\
\hline Mid third & 1 & 5.56 \\
\hline Distal third & 3 & 16.67 \\
\hline \begin{tabular}{l} 
Stomach (11) \\
\hline $\begin{array}{l}\text { Upper stomach (cardia and } \\
\text { upper body) }\end{array}$
\end{tabular} & 3 & 16.67 \\
\hline $\begin{array}{l}\text { Middle stomach (angle, } \\
\text { middle body) }\end{array}$ & 5 & 27.78 \\
\hline $\begin{array}{l}\text { Lower stomach (lower body, } \\
\text { antrum, pylorus) }\end{array}$ & & \\
\hline
\end{tabular}

endoscopy in patients aged $>50$ years. The public health training and awareness campaigns about gastric cancer could explain the higher proportion in this age group. Globally screening for gastroesophageal cancers is recommended in dyspeptic patients aged $>40$ years $[11,12]$ and this is in keeping with our findings.

Our study reveals a very high prevalence of organic dyspepsia of $>90 \%$ which could imply that by the nature of our study setting being a national referral hospital, the most severe and persistent symptomatic patients could possibly be the ones seeking care at the national referral hospital, and hence, likely to have more organic causes. This, therefore, is a potential source of bias. Second the majority of referrals often come late, due to either financial constraints associated with the procedure or perceptions such as disease progression after biopsy. All these could explain the high rate of organic dyspeptic findings being representative of late presentation. However, when the prevalence of organic dyspepsia among patients with dyspepsia is compared with studies conducted in the African region, there is a striking similarity. In Kenya, the prevalence was slightly lower at $8 \%$ [7], implying a $92 \%$ prevalence of organic dyspepsia. while in a similar study in Ibadan, Nigeria, the prevalence of functional dyspepsia among dyspeptic patients was lower at 6\% [13], implying a prevalence of organic dyspepsia of $94 \%$. Overall, the global prevalence of functional dyspepsia is approximately $11 \%$ to $29.2 \%$ [3]. Our findings along with the studies in SSA demonstrate that the majority of dyspepsia is due to an organic cause.

The finding that gastritis was the most prevalent condition in our study population was not surprising as it is similar to the described findings in other regions of Uganda [6] and

SSA $[14,15]$. Not surprisingly, there was no association between the age and sex in gastritis or any other endoscopic findings among the study population.

Gastroesophageal cancer presentation, especially in early stages, mimics any other benign causes of dyspepsia [16], hence increasing the likelihood of missed early diagnosis [17] in patients with dyspepsia. In our study population, the preval- 
ence of gastroesophageal cancers among patients with dyspepsia was rather strikingly high at $11.32 \%$ when compared to larger studies in Hong Kong [18] and Canada [19], in which the prevalence was less than $1 \%$. However, it should be noted that the above studies had a significantly larger sample size. Nevertheless, these findings raise a red flag for a potentially higher prevalence of gastroesophageal malignancies among dyspeptic patients in Uganda. This further emphasizes the need for more purposeful investigation for gastroesophageal malignancies in patients in SSA who present with dyspepsia, especially in the fourth decades and above.

Its projected that SSA will have the highest burden of gastroesophageal cancers globally by 2030 [5] and this is a red flag our results seem to agree with. Typically esophageal cancer presents with dysphagia and patients with dysphagia were excluded; however, it's important to recognize that dyspepsia, especially retrosternal pain, may point towards early esophageal cancer, hence requiring early screening [20].

\section{Conclusions}

More than $90 \%$ of dyspepsia in patients seeking care in Mulago hospital is associated with a structural/organic lesion, including gastritis, among other causes. There is a higher prevalence of gastroesophageal cancer among patients with dyspepsia who are aged $>50$ years. We recommend that patients aged $>50$ years who have dyspepsia that has not been investigated undertake a mandatory endoscopic evaluation as the likelihood of having a gastroesophageal malignancy in this population is very high.

\section{Acknowledgements}

The authors thank the wonderful staff of the Endoscopy Unit of Mulago National Referral Hospital.

\section{Competing interests}

The authors declare that they have no conflict of interest.

\section{References}

[1] Ford AC, Bercik P, Morgan DG et al. The Rome III criteria for the diagnosis of functional dyspepsia in secondary care are not superior to previous definitions. Gastroenterology 2014; 146: 932-940; quiz e914-935
[2] Talley N], Zinsmeister AR, Schleck CD et al. Dyspepsia and dyspepsia subgroups: a population-based study. Gastroenterology 1992; 102: 1259-1268

[3] Mahadeva S, Goh K-L. Epidemiology of functional dyspepsia: a global perspective. World J Gastroenterol 2006; 12: 2661-2666

[4] Lee Y], Adusumilli G, Kyakulaga F et al. Survey on the prevalence of dyspepsia and practices of dyspepsia management in rural Eastern Uganda. Heliyon 2019; 5: e01644

[5] Singh P, Irabor D, Adedeji O. Gastrointestinal cancers in Sub-Saharan Africa.Adedeji O. Cancer in Sub-Saharan Africa: Current Practice and Future. 1. Aufl. UK: Springer International Publishing; 2017: doi:10.1007/978-3-319-52554-9_9

[6] Obayo S, Muzoora C, Ocama P et al. Upper gastrointestinal diseases in patients for endoscopy in South-Western Uganda. Afr Health Sci 2015; 15: 959-966

[7] Yuo PO, Some FF, Kiplagat J. Upper gastrointestinal endoscopy findings in patients referred with upper gastrointestinal symptoms in Eldoret, Kenya: A retrospective review. East African Med J 2014; 91 : 267-273

[8] Onyekwere CA, Hameed H, Anomneze EE et al. Upper gastrointestinal endoscopy findings in Nigerians: a review of 170 cases in Lagos. Nigerian Postgrad Med J 2008; 15: 126-129

[9] Ogwang M. Dyspepsia: endoscopy findings in Uganda. Tropical Doctor 2003; 33: 175-177

[10] Stanghellini V. Functional dyspepsia and irritable bowel syndrome: beyond Rome IV. Digest Dis 2017; 35: 14-17

[11] Choi KS, Suh M. Screening for gastric cancer: the usefulness of endoscopy. Clin Endosc 2014; 47: 490-496

[12] Liou JM, Lin JT, Wang HP et al. The optimal age threshold for screening upper endoscopy for uninvestigated dyspepsia in Taiwan, an area with a higher prevalence of gastric cancer in young adults. Gastrointest Endosc 2005; 61: 819-825

[13] Olokoba AB, Salawu FK, Vickola JA. Functional dyspepsia in Yola, Nigeria. Res J Health Sci 2015: 3

[14] Ayana SM, Swai B, Maro VP. Upper gastrointestinal endoscopic findings and prevalence of Helicobacter pylori infection among adult patients with dyspepsia in northern Tanzania. Tanzania J Health Res 2014: 16

[15] Agyei-Nkansah A, Duah A, Alfonso M. Indications and findings of upper gastrointestinal endoscopy in patients presenting to a District Hospital, Ghana. Pan Afr Med J 2019; 34: 82-82

[16] McColl KEL, Kidd J, Gillen D. Gastric cancer in patients with benign dyspepsia. Gut 2000; 47: 741

[17] Schmidt N, Peitz U, Lippert $\mathrm{H}$ et al. Missing gastric cancer in dyspepsia. Aliment Pharmacol Therapeut 2005; 21: 813-820

[18] Sung JJ, Lao WC, Lai MS et al. Incidence of gastroesophageal malignancy in patients with dyspepsia in Hong Kong: implications for screening strategies. Gastrointest Endosc 2001; 54: 454-458

[19] Breslin NP, Thomson ABR, Bailey R] et al. Gastric cancer and other endoscopic diagnoses in patients with benign dyspepsia. Gut 2000; 46: 93

[20] Bird-Lieberman EL, Fitzgerald RC. Early diagnosis of oesophageal cancer. Br J Cancer 2009; 101: 1-6 